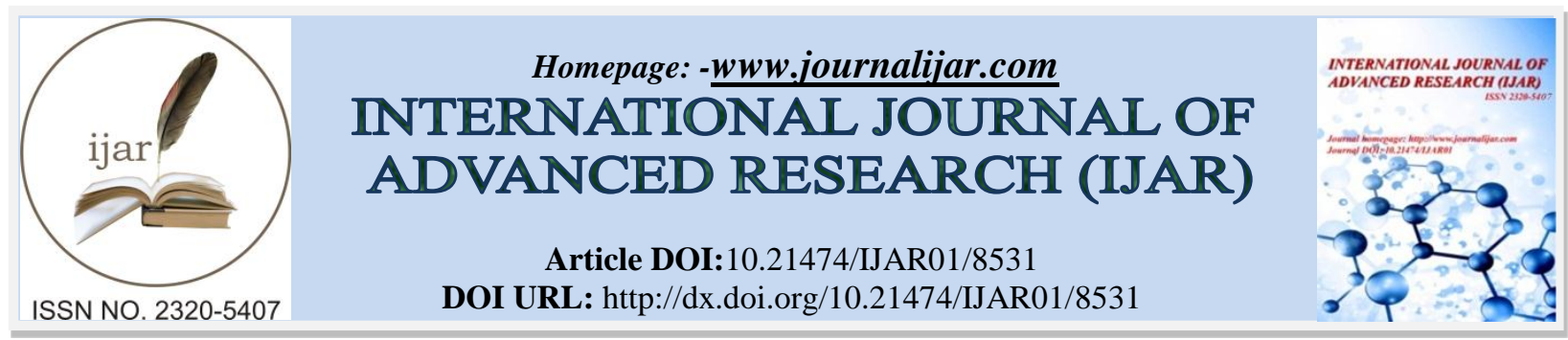

RESEARCH ARTICLE

\title{
PERCIEVED BARRIERS AND PREFERENCES IN PHYSICAL ACTIVITY AMONG FACULTY AND STAFF IN THE PHILIPPINE STATE UNIVERSITY.
}

Francis Jose S. Dela Cruz.

Laguna State Polytechnic University, College of Teacher Education Siniloan Campus.

\section{Manuscript Info}

Manuscript History

Received: 06 December 2018

Final Accepted: 08 January 2019

Published: February 2019

Key words:-

Perceived Barriers, Physical Activity,

Faculty and Staff.

\begin{abstract}
This study aims to determine the perceived barriers and preferences in physical activity of Laguna State Polytechnic University (LSPU) faculty and staff. This study utilized the descriptive research design, The study surveyed 268 faculty and staff from the four LSPU campuses. Most of the respondents tend to feel that their day is so busy and they don't think that they can make time to include physical activity in their regular schedule, and that doing physical activity takes their time away from other more important commitments such as time for themselves and family. Most respondents also indicate that they do want to start to have more exercise, but just can't seem to get started. On the other hand, most of the respondents are less likely to feel embarrassed on how they will look when they exercise with others. Most of the respondents are also less likely to say that they know too many people who have hurt themselves by overdoing exercise. Furthermore, respondents are less likely to be concerned that they might get injured or have a heart attack. Knowing these perceived barriers and exercise preferences will greatly help in developing a comprehensive physical fitness program for LSPU faculty and staff.
\end{abstract}

Copy Right, IJAR, 2019,. All rights reserved.

\section{Introduction:-}

Various studies have shown the many benefits of physical activities to our overall health. Engaging in physical activities have been shown to prevent age-related diseases such as cardiovascular health diseases (CHD), type 2 diabetes mellitus, obesity, ischemic heart diseases, stroke and other non-communicable diseases (Reiner, Niermann, Jekauc \& Woll, 2013). It has also been shown that people who engage in physical activities regularly display a better quality of life and mood (Penedo \& Dahn, 2005). There is also evidence that engagement in physical activities can reduce stress and can even produce a protective effect against diseases related to psychological stress (Rimmele et al., 2007). People who engage in physical activities tend to be able to recover to psychological stress more quickly.

Because of the recognized benefits of engagement physical activities for employees, it is therefore highly important for both faculty and staff to participate in physical activity programs. However, to further promote participation in physical activities and physical fitness programs, one should take note of the interests of particular groups including physical activity preferences as well as the perceived barriers in engaging in physical activity.

Physical activity preference is an important aspect in developing appropriate physical activity programs for faculty and staff so that they will be more interested in joining the program based on Civil Service Commission 
Memorandum Circular No. 8 Series 1992 (www.web.csc.gov.ph). This MC regarding the Physical and Mental Fitness program for government personnel dated September 30, 1992. Physical activity programs and interventions may be more effective if development and implementation of such programs are grounded on the needs and interests of the target group, in this case faculty and staff of LSPU.

In addition, though there is a wide range of fitness facilities on campus, it is unclear whether these facilities are being used by constituents to engage in physical activity. Hence, perceived barriers to physical activity should be identified to be able to determine an intervention that could result to increased engagement in physical activities for faculty and staff.

In view of this, this study aims to determine the physical activity preferences of Laguna State Polytechnic University (LSPU) faculty and staff and the perceived barriers in engaging in physical activity. The results obtained from this objective were used in developing a Comprehensive Physical Fitness Development Program for LSPU faculty and staff.

Objectives of the study:-

Specifically, this study aims to:

1. Determine the physical activities preferred by the faculty and staff of LSPU

2. Determine the most and least preferred physical activity of the respondents.

3. Determine significant relationship between demographic profile of the faculty and staff and their physical activity preferences.

4. Determine significant differences on the physical activity preferences of LSPU faculty and staff.

5.To develop a comprehensive fitness program for LSPU faculty and staff.

\section{Methodology:-}

This study utilized the descriptive research design particularly the survey method in determining the demographic profile of the faculty and staff which helped in describing the characteristics of the population being studied. This research method was also used in identifying the faculty and staff's physical activity preferences and perceived barriers.

The respondents of this study consisted of faculty and staff from the four campuses of the Laguna State Polytechnic University, namely Siniloan with 200 respondents, Sta. Cruz with 359 respondents, San Pablo with 257 respondents and Los Baños with 150 respondents during the Academic Year 2015 - 2016.

A total of 480 questionnaires were distributed to the faculty and staff from all of the LSPU campuses. Among the distributed questionnaires, 268 were returned and/or retrieved for analysis.

\section{Findings:-}

A total of 268 questionnaires were returned and analyzed. Most of the respondents are female comprising 63.06\% of the total. There is almost an equal percentage of respondents from both the administrative staff and faculty. Most of the respondents are married comprising $57.46 \%$ of the total (Table 1)

Table 1:-Distribution of the Respondents according to their Profile.

\begin{tabular}{|c|c|c|c|c|}
\hline Variable & Classification & Frequency & Percent & Rank \\
\hline \multirow[t]{4}{*}{ Campus } & Siniloan & 70 & $26.12 \%$ & \begin{tabular}{l|l} 
& 2 \\
\end{tabular} \\
\hline & Santa Cruz & 89 & $33.21 \%$ & 1 \\
\hline & San Pablo & 70 & $26.12 \%$ & 2 \\
\hline & Los Baños & 39 & $14.55 \%$ & 4 \\
\hline \multirow[t]{5}{*}{ Age Group } & 22 years old and below & 17 & $6.34 \%$ & 5 \\
\hline & 23 - 28 years old & 59 & $22.01 \%$ & 2 \\
\hline & $29-38$ years old & 80 & $29.85 \%$ & 1 \\
\hline & $39-49$ years old & 58 & $21.64 \%$ & 3 \\
\hline & 50 years old and above & 54 & $20.15 \%$ & 4 \\
\hline \multirow[t]{2}{*}{ Sex } & Female & 169 & $63.06 \%$ & 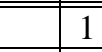 \\
\hline & Male & 99 & $36.94 \%$ & 2 \\
\hline
\end{tabular}




\begin{tabular}{|l|l|l|l|l|}
\hline \multirow{4}{*}{ Civil Status } & Single & 100 & $37.31 \%$ & 2 \\
\cline { 2 - 5 } & Married & 154 & $57.46 \%$ & 1 \\
\cline { 2 - 5 } & Widowed & 11 & $4.10 \%$ & 3 \\
\cline { 2 - 5 } & Separated & 3 & $1.12 \%$ & 4 \\
\hline \hline \multirow{2}{*}{ Nature of Work } & Admin Staff & 127 & $47.39 \%$ & 2 \\
\cline { 2 - 5 } & Faculty & 141 & $52.61 \%$ & 1 \\
\hline
\end{tabular}

Respondents' Current Physical Activity Participation

Respondents were asked their current physical activity practices such as the exercises and sports activities they currently participate in. The top 3 exercises that respondents currently participate in are walking (62.69\%), running or jogging (31.34\%), and Zumba (22.39\%). Only $12.31 \%$ currently participate in team sports (Table 2 ).

Table 2:-Distribution of the physical activities that respondents participate in.

\begin{tabular}{|l|l|l|l|}
\hline Exercise & Frequency & Percent & Rank \\
\hline Walk & 168 & $62.69 \%$ & 1 \\
\hline Run/Jog & 84 & $31.34 \%$ & 2 \\
\hline Zumba & 60 & $22.39 \%$ & 3 \\
\hline Dance & 37 & $13.81 \%$ & 4 \\
\hline Team Sports & 33 & $12.31 \%$ & 5 \\
\hline Others & 30 & $11.19 \%$ & 6 \\
\hline Weight Lifting & 21 & $7.84 \%$ & 7 \\
\hline Aerobics & 16 & $5.97 \%$ & 8 \\
\hline Swim & 14 & $5.22 \%$ & 9 \\
\hline Table Tennis & 4 & $1.49 \%$ & 10 \\
\hline
\end{tabular}

When asked about the frequency in which they do their exercise/physical activity, most of the respondents answered that they do exercise once (26.23\%) or twice a week (31.34\%). Only $11.19 \%$ exercise very rarely. Hence, more than $50 \%$ of the respondents have regular exercises per week (Table 3 )

Table 3:-Number of sessions per week the respondents engage in physical activity.

\begin{tabular}{|l|l|l|l|}
\hline Number of Times & Frequency & Percent & Rank \\
\hline Twice & 84 & $31.34 \%$ & 1 \\
\hline Once & 70 & $26.12 \%$ & 2 \\
\hline Thrice & 48 & $17.91 \%$ & 3 \\
\hline More than four times & 36 & $13.43 \%$ & 4 \\
\hline Very Rare & 30 & $11.19 \%$ & 5 \\
\hline
\end{tabular}

More than half of the respondents do exercise for only $0-1$ hour per week. Most of the respondents exercise for less than an hour $(44.78 \%)$ or for one hour per week only (41.79\%). Less than $10 \%(4.1 \%)$ do exercise for 3 or more hours per week (Table 4).

Table 4:-Number of hours per week the respondents engage in physical activity.

\begin{tabular}{|l|l|l|l|}
\hline Number of Hours & Frequency & Percent & Rank \\
\hline Less than an hour & 120 & $44.78 \%$ & 1 \\
\hline 1 hour & 112 & $41.79 \%$ & 2 \\
\hline 2 hours & 25 & $9.33 \%$ & 3 \\
\hline 3 hours & 7 & $2.61 \%$ & 4 \\
\hline More than 4 hours & 4 & $1.49 \%$ & 5 \\
\hline
\end{tabular}

However, when asked if they feel they get the right amount of exercise per week, most of the respondents (61.19\%) feel that they get too little exercise (Table 5). 
Table 5:-Amount of exercise per week the respondents perceive they are getting.

\begin{tabular}{|l|l|l|l|}
\hline Amount of Exercise & Frequency & Percent & Rank \\
\hline Too little & 164 & $61.19 \%$ & 1 \\
\hline About right & 92 & $34.33 \%$ & 2 \\
\hline Too much & 12 & $4.48 \%$ & 3 \\
\hline
\end{tabular}

\section{Respondents' Physical Activity Preferences:-}

Aside from the exercises and sports activities they currently participate in, respondents were also asked what their preferred physical activities are. The top 3 most preferred exercises are walking for fitness (4.33 weighted mean), running/jogging (4.18 weighted mean), and Zumba (3.85 weighted mean). Most of the respondents tend to strongly agree to walking for fitness (134/268) and running/jogging (114/268) as their preferred exercise. This actually reflects the top 3 exercises they currently participate in. Respondents also tend to prefer aerobics and swimming as their preferred exercises with a weighted mean of 3.72 and 3.65, respectively. Weight lifting is the least preferred exercise among the respondents with a 3.02 weighted mean (Table 6)

Table 6:-Respondents' level of preference to the popular exercises .

\begin{tabular}{|l|l|l|l|}
\hline Exercises & Weighted Mean & Verbal Interpretation & Rank \\
\hline Walking for Fitness & 4.33 & Strongly Agree & 1 \\
\hline Running/Jogging & 4.18 & Agree & 2 \\
\hline Zumba & 3.85 & Agree & 3 \\
\hline Aerobics & 3.72 & Agree & 4 \\
\hline Swimming & 3.65 & Agree & 5 \\
\hline Weight Lifting & 3.02 & Neutral & 6 \\
\hline
\end{tabular}

Aside from their preferred exercise, respondents were also asked what their preferred sports activities are. The top 3 popular sports activities among the respondents are badminton (3.93 weighted mean), volleyball (3.66 weighted mean), and basketball (3.52 weighted mean). Baseball and soccer ranked as the least preferred sports activities among the respondents with a weighted mean of only 3.08 and 3.10, respectively (Table 7).

Table 7:-Respondents' preferred sports activities.

\begin{tabular}{|l|l|l|c|}
\hline Preferred Sports & Weighted Mean & Verbal Interpretation & Rank \\
\hline Badminton & 3.93 & Agree & 1 \\
\hline Volleyball & 3.66 & Agree & 2 \\
\hline Basketball & 3.52 & Agree & 3 \\
\hline Table Tennis & 3.43 & Agree & 4 \\
\hline Tennis & 3.32 & Neutral & 5 \\
\hline Bowling & 3.24 & Neutral & 6 \\
\hline Football & 3.11 & Neutral & 7 \\
\hline Soccer & 3.10 & Neutral & 8 \\
\hline Baseball & 3.08 & Neutral & 9 \\
\hline
\end{tabular}

When asked on the number of sessions per week they want to do exercise, almost half of the respondents prefer to have three sessions per week (42.54\%). This is actually more than the number of sessions per week they currently do exercise which is mostly only twice a week. Hence, respondents want to have a more frequent exercise than what they currently practice (Table 8).

Table 8:-Distribution of the Respondents in terms of their preferred number of sessions per week to engage in a physical fitness program.

\begin{tabular}{|l|l|l|l|}
\hline Preferred Frequency & Frequency & Percent & Rank \\
\hline Thrice a week & 114 & $42.54 \%$ & 1 \\
\hline Twice a week & & & \\
\hline Once a week & 77 & $28.73 \%$ & 2 \\
\hline More than four times per week & 59 & $22.01 \%$ & 3 \\
\hline
\end{tabular}


Most of the respondents prefer to do exercise for one hour per session $(60.45 \%)$. Less than $5 \%$ of the respondents prefer to have 3 or more hours per session for exercise $(1.49 \%)$.

Table 9:-Distribution of the Respondents in terms of their preferred number of hours per session to engage in a

\begin{tabular}{|l|l|l|l|}
\hline Perceived Barriers & Weighted Mean & $\begin{array}{l}\text { Average Weighted } \\
\text { Mean }\end{array}$ & $\begin{array}{l}\text { Verbal } \\
\text { Interpretation }\end{array}$ \\
\hline
\end{tabular}

physical fitness program.

\begin{tabular}{|l|l|l|l|}
\hline Preferred Duration & Frequency & Percent & Rank \\
\hline 1 hour & 162 & $60.45 \%$ & 1 \\
\hline Less than an hour & 66 & $24.63 \%$ & 2 \\
\hline 2 hours & 36 & $13.43 \%$ & 3 \\
\hline 3 hours & 3 & $1.12 \%$ & 4 \\
\hline More than 4 hours & 1 & $0.37 \%$ & 5 \\
\hline
\end{tabular}

Lastly, majority of the respondents (64.18\%) prefer to have their exercise in the morning.

This preference may be because respondents wanted to do the exercise when they still have the energy in the morning instead of exercising in the afternoon when they are tired from their work during the day.

Table 10:-Distribution of the Respondents in terms of their preferred time of the day to engage in a physical fitness program.

\begin{tabular}{|l|l|l|l|}
\hline Preferred Time & Frequency & Percent & Rank \\
\hline Morning & 172 & $64.18 \%$ & 1 \\
\hline Afternoon & 96 & $35.82 \%$ & 2 \\
\hline
\end{tabular}

\section{Perceived Barriers in Participating in Physical Activity:-}

The respondent were each asked the level of their attitude on the statements which they perceive to hinder them in participating in physical activity. As stated in Chapter 3, scoring 5 or above in any of the seven specified barriers means that this is an important concert they need to overcome. Weighted means were computed for each statement then the weighted means were added based on the category the statement falls in. A score of 5 or above in any category means that this is an important barrier for the respondents to overcome. This method of scoring is specified by the source material of the questionnaire (N.a., Centers for Disease Control and Prevention, 2014).

Among the seven recognized barriers, lack of time (2.26) and lack of willpower (2.27) are the top 2 barriers that respondents perceive to be hindering them from participating in physical activity. On the other hand, their least concern is fear of injury scoring only 2.86 


\begin{tabular}{|c|c|c|c|}
\hline $\begin{array}{l}\text { Lack of Time } \\
\text { Q1. My day is so busy now; I just don't think I } \\
\text { can make the time to include physical activity } \\
\text { in my regular schedule. } \\
\text { Q8. Physical activity takes too much time away } \\
\text { from other commitments - time, work, family, } \\
\text { etc. } \\
\text { Q15. My free times during the day are too short } \\
\text { to include exercise. }\end{array}$ & $\begin{array}{l}2.01 \\
2.50 \\
2.27\end{array}$ & 2.26 & $\begin{array}{l}\text { Somewhat } \\
\text { Unlikely }\end{array}$ \\
\hline $\begin{array}{l}\text { Social Influence } \\
\text { Q2. None of my family members or friends like } \\
\text { to do anything active, so I don't have a chance } \\
\text { to exercise. } \\
\text { Q9. I'm embarrassed about how I will look } \\
\text { when I exercise with others. } \\
\text { Q16. My usual social activities with family or } \\
\text { friends do not include physical activity. }\end{array}$ & $\begin{array}{l}2.90 \\
2.37\end{array}$ & 2.58 & $\begin{array}{l}\text { Somewhat } \\
\text { Likely }\end{array}$ \\
\hline $\begin{array}{l}\text { Lack of Energy } \\
\text { Q3. I'm just too tired after work to get any } \\
\text { exercise. } \\
\text { Q10. I don't get enough sleep as it is. I just } \\
\text { couldn't get up early or stay up late to get some } \\
\text { exercise. } \\
\text { Q17. I'm too tired during the week and I need } \\
\text { the weekend to catch up on my rest. }\end{array}$ & $\begin{array}{l}2.20 \\
2.54 \\
2.33\end{array}$ & 2.35 & $\begin{array}{l}\text { Somewhat } \\
\text { Unlikely }\end{array}$ \\
\hline $\begin{array}{l}\text { Lack of Willpower } \\
\text { Q4. I've been thinking about getting more } \\
\text { exercise, but I just can't seem to get started. } \\
\text { Q11. It's easier for me to find excuses not to } \\
\text { exercise than to go out to do something. } \\
\text { Q18. I want to get more exercise, but I just } \\
\text { can't seem to make myself stick to anything. }\end{array}$ & $\begin{array}{l}2.01 \\
2.64 \\
2.18\end{array}$ & 2.27 & $\begin{array}{l}\text { Somewhat } \\
\text { Unlikely }\end{array}$ \\
\hline $\begin{array}{l}\text { Fear of Injury } \\
\text { Q5. I'm getting older so exercise can be risky. } \\
\text { Q12. I know of too many people who have hurt } \\
\text { themselves by overdoing it with exercise. } \\
\text { Q19. I'm afraid I might injure myself or have a } \\
\text { heart attack. }\end{array}$ & $\begin{array}{l}2.82 \\
2.89 \\
2.89\end{array}$ & 2.86 & $\begin{array}{l}\text { Somewhat } \\
\text { Likely }\end{array}$ \\
\hline $\begin{array}{l}\text { Lack of Skills } \\
\text { Q6. I don't get enough exercise because I have } \\
\text { never learned the skills for any sport. } \\
\text { Q13. I really can't see learning a new sport at } \\
\text { my age. } \\
\text { Q20. I'm not good enough at any physical } \\
\text { activity to make it fun. }\end{array}$ & $\begin{array}{l}2.81 \\
2.83 \\
2.74 \\
\end{array}$ & 2.79 & $\begin{array}{l}\text { Somewhat } \\
\text { Likely }\end{array}$ \\
\hline $\begin{array}{l}\text { Lack of Resources/ Facilities } \\
\text { Q7. I don't have access to jogging trails, } \\
\text { swimming pools, bike paths, etc. } \\
\text { Q14. It's just too expensive. You have to take a } \\
\text { class or join a club or buy the right equipment. } \\
\text { Q21. If we had exercise facilities and showers } \\
\text { at work, then I would be more likely to } \\
\text { exercise. }\end{array}$ & $\begin{array}{l}2.68 \\
2.80 \\
2.22\end{array}$ & 2.5 & $\begin{array}{l}\text { Somewhat } \\
\text { Likely }\end{array}$ \\
\hline
\end{tabular}


Among the statements, most of the respondents tend to feel that their day is so busy and they don't think that they can make time to include physical activity in their regular schedule (2.01 weighted mean) and that doing physical activity takes their time away from other more important commitments such as time for themselves and family ( 2.50 weighted mean). Most respondents also indicate that they do want to start to have more exercise, but just can't seem to get started.

On the other hand, most of the respondents are less likely to feel embarrassed on how they will look when they exercise with others ( 2.90 weighted mean). Most of the respondents are also less likely to say that they "know too many people who have hurt themselves by overdoing exercise" ( 2.89 weighted mean). Furthermore, respondents are less likely to be concerned that they might get injured or have a heart attack ( 2.89 weighted mean) on Table 11 .

\section{Conclusion:-}

Most of the respondents are female comprising $63.06 \%$ of the total. There is almost an equal percentage of respondents from both the administrative staff and faculty. Most of the respondents are married comprising 57.46\% of the total.

Based on the results from the questionnaire, the top three (3) physical activity that respondents currently participate in are walking, running/jogging and Zumba. Most of the respondents have one to two sessions doing exercises per week for less than an hour. They also feel that they get too little exercise per week.

This is also reflected as their top three (3) most preferred exercise. With regards to sports activities, on the other hand, the top three (3) most preferred sports are badminton, volleyball, and basketball. When they were asked their preferred number of session and hours per week for exercises, respondents wanted to have a more regular schedule for exercises preferring to do three sessions per week doing one hour per session.

With regards to perceived barriers to physical activities, the most important concern that respondents feel they need to overcome are lack of time and lack of willpower. Most feel that they are so busy that they cannot find time to fit exercise into their regular schedules. Most also indicated that they have been wanting to start doing regular exercise but just can't seem to get started most likely due to time constraints.

\section{Reference:-}

1. Bogaert, I., de Martelaer, K., Deforche, B., Clarys, P., \& Zinzen, E. (2014). Associations between different types of physical activity and teachers' perceived mental, physical, and work-related health. BMC Public Health, 14.

2. Buchan, D., Ollis, S., Thomas, N., \& Baker, J. (2012). Physical Activity Behaviour: An Overview of Current and Emergent Theoretical Practices. Journal of Obesity, 2012.

3. Deci, E. L., \& Ryan, R. M. (1985). Intrinsic motivation and self-determination in human behavior. New York: Plennum Press.

4. Erick, P. N., \& Smith, D. R. (2011). A systematic review of musculoskeletal disorders among school teachers. BMC Musculoskelet Disord, 12, 260.

5. Healy, G. N., Wijndaele, K., Dunstan, D. W., Shaw, J. E., Salmon, J., Zimmet, P. Z., \& Owen, N. (2008). Objectively measured sedentary time, physical activity, and metabolic risk. Diab Care, 31(2), 369-371.

6. N.a. (2014). Self-Determination Theory. Retrieved June 15, 2014, from http://www.selfdeterminationtheory.org/

7. Parry, S., \& Straker, L. (2013). The contribution of office work to sedentary behaviour associated risk. BMC Public Health, 13.

8. Penedo, F., \& Dahn, J. (2005). Exercise and well-being: a review of mental and physical health benefits associated with physical activity. Curr Opin Psychiatry, 18, 189-193.

9. Reiner, M., Niermann, C., Jekauc, D., \& Woll, A. (2013). Long-term health benefits of physical activity - a systematic review of longitudinal studies. BMC Public Health, 13(813).

10. Rimmele, U., Zellweger, B., Marti, B., Seiler, R., Mohiyeddini, C., Ehlert, U., \& Heinrichs, M. (2007). Trained men show lower cortisol, heart rate and psychological responses to psychosocial stress compared with untrained men. Psychoneuroendocrinology, 32, 627-635.

11. Ryan, R. M., \& Deci, E. L. (2000). Intrinsic and extrinsic motivations: Classic definitions and new directions. Contemporary Educational Psychology, 25, 54-67. 
12. Ryan, R. M., William, G. C., Patrick, H., \& Deci, E. L. (2009). Self-determination theory and physical activity: The dynamics of motivation in development and wellness. Hellenic Journal of Psychology, 6, 107-124.

13. Sinyor, D., Schwartz, S., Peronnet, F., Brisson, G., \& Seraganian, P. (1983). Aerobic fitness level and reactivity to psychosocial stress: physiological, biochemical, and subjective measures. Psychosom Med, 45, 205-217.

14. Ussher, M., Stanbury, L., Cheeseman, V., \& Faulkner, G. (2007). Physical activity preferences and perceived barriers to activity among persons with severe mental illness in the United Kingdom. Psychiatric Services, 58(3), 405-408.

15. Whipple, K., Kinney, J., \& Kattenbraker, M. (2008). Maintenance of physical activity among faculty and staff in University settings. The Health Educator, 40(1), 21-28.

16. Yang, X., Ge, C., Hu, B., Chi, T., \& Wang, L. (2009). Relationship between quality of life and occupational stress among teachers. Public Health, 123(11), 750-755. 